\title{
Resilience Pivots: Stability and Identity in a Social-Ecological-Cultural System
}

\author{
Stephanie J. Rotarangi ${ }^{1}$ and Janet Stephenson ${ }^{1}$
}

\begin{abstract}
How is cultural resilience achieved in the face of significant social and ecological change? Is resilience compatible with changed structures, functions, and feedbacks as long as identity is maintained? The concept of cultural resilience has been less explored than its older siblings ecological resilience, social resilience, and social-ecological resilience. We seek to redress the balance, drawing from resilience thinking to examine how a New Zealand Māori tribal group of landowners retained strong cultural identity and connectedness to their land despite enduring significant changes in land use, economy, tenure, and governance. The landowners negotiated radical transformations in the ecology and land use of their home lands on terms that supported matters of cultural importance. The key resilience concepts of adaptation and transformation were helpful in analyzing the trajectory of change, but fell short of representing the elements of stability that supported the cultural resilience of the landowners. The concept of resilience pivots was designed to address this conceptual gap, and to offer another heuristic to resilience thinking by focusing on stability rather than change. Resilience pivots are those elements of a resilient system that remain stable despite adaptation or even transformation of other elements of that system, and in doing so support the maintenance of the system's distinctive identity.
\end{abstract}

Key Words: cultural resilience; ecological resilience; forestry; identity; New Zealand Maori; resilience; social resilience; stability

\section{INTRODUCTION}

The extension of resilience concepts from ecological systems to social-ecological systems has led to important insights into human-environment relationships. However, further refinement is necessary to better align the systems-based epistemology of resilience with normative issues, and in particular the question of 'resilience of what and for whom?' (Cote and Nightingale 2012:475). This question is particularly salient for indigenous societies, where the long-established relationships with particular environments mean that natural and cultural systems are highly interactive, and "values of place, identity and community ... constitute and constrain how humans interact with their environment" (Adger et al. 2010:548). The term "cultural resilience" has emerged to refer to this continuity of a coconstituted set of long-term relationships between the cultural identity of a people and the set of social-ecological relationships within which this identity was founded.

Many indigenous societies have faced overwhelming transformations in their societal and ecological systems over the past 100-200 years, and yet have managed to maintain "key elements of structure and identity that preserve [their] distinctness," a phrase use by Fleming and Ledogar (2008:3) to describe cultural resilience. These situations offer potentially fruitful case studies to explore the relationship between the degree of integrity of a social-ecological system (resilience of what?) and the retention of cultural structures and identity (resilience for whom?). Furthermore, given the succession of change drivers faced by many indigenous cultures, these situations allow us to explore the factors involved in generalized resilience to multiple impacts (Folke et al. 2010) as opposed to those factors involved in specified resilience (resilience of what, to what?; Carpenter et al. 2001).

In this paper we build on a case study ${ }^{[1]}$ that examined the perspectives and responses of a New Zealand Māori tribal group to 150 years of change in land-use and socio-political structures, with a particular focus on the past 50 years. The objective of the study was to investigate how the Māori owners of the Lake Taupō Forest Trust (LTFT) lands responded to a period of extensive social and environmental change. At around 32,000 hectares (81,000 acres), the LTFT lands form a significant portion of the landholdings of Ngāti Tūwharetoa, a tribe of strong mana (authority, prestige) and unique cultural identity who occupy the area around Lake Taupō, New Zealand's largest lake (Fig. 1). In the late 1960s, these lands were leased on a long-term basis by a forestry company, cleared of most native vegetation, and planted with a single-species, non-native forest.

Fig. 1. Lake Taupō Forest, established on Lake Taupō Forest Trust lands adjacent to Lake Taupō in the central North Island of New Zealand.

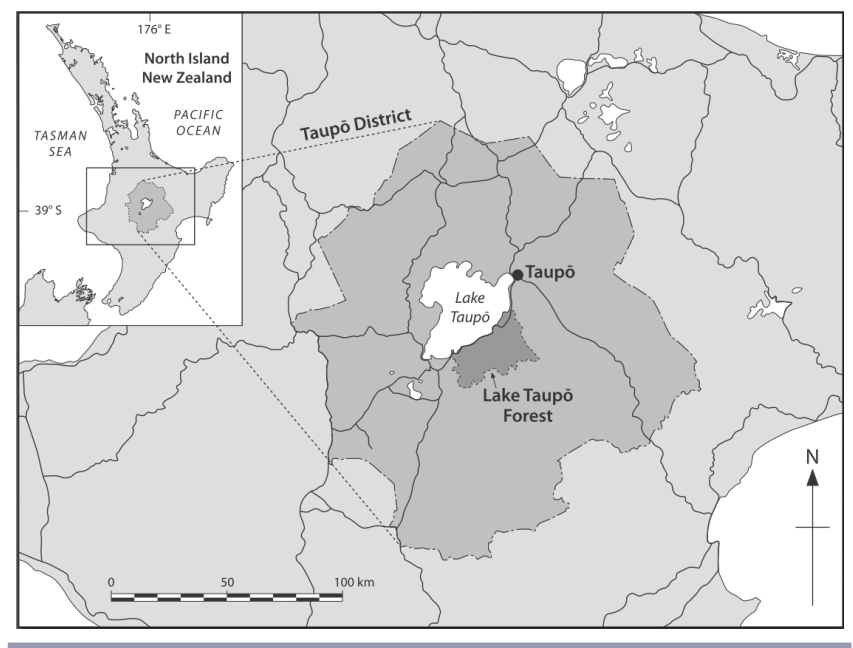


At the outset of this research it was hypothesized that the exotic forest would be antithetical to the cultural values of the owners, and would be generally considered an alienating ecosystem and management regime. In resilience terms, and building on Davidson's (2010) assertion that the only possible responses to disturbance were resilience, adaptation, or transformation, we were interested in how the transformations in the social-ecological system had impacted on the cultural resilience of the Māori owners.

\section{RESILIENCE CONCEPTS}

There is no single definition of resilience, or agreed limits to its application (CARRI 2009), but the most commonly used description is Walker et al.'s (2004:2) definition of "the capacity of a system to absorb disturbance and reorganize while undergoing change so as to still retain essentially the same function, structure, identity and feedbacks," or the apparently slight but important variation of "the capacity of a system to undergo change while still maintaining the same structure, functions and feedbacks, therefore identity" (Walker et al. 2010:187). In the more recent definition, the retention of identity is the defining feature of a resilient system. We will return to this point.

As "a collection of ideas about how to interpret complex systems" rather than a theory (Anderies et al. 2006:7), present-day resilience thinking is largely concerned with understanding a system's persistence in the face of change, and its innovation or ability to change into more desirable states when required (Folke 2006). The resilience concepts of stability, adaptation, and transformation have made a major contribution to understanding the processes of change in response to disturbance in ecological, social, and social-ecological systems. Adaptation involves changes to certain elements of the system that allow the system to retain the same regime overall, and from a social-ecological perspective it may involve changes in systems of governance or management of natural systems (Berkes and Turner 2006). Where external shocks are significant, a social-ecological system may be transformed into an entirely new regime, with new structures, functions, and identity. In some circumstances, human agency is likely to play a role in this transformation, particularly when the ecological, economic, and/or social conditions make the current system untenable or undesirable (Walker et al. 2004, Anderies et al. 2006), but transformations can also be forced by external circumstances (Folke et al. 2010). Actors within a social-ecological system are not simply passive respondents to change, but nor are they allpowerful (Berkes et al. 2003). Their role in adaptation dynamics will be mediated by such things as the scope and time frame of the change cycle, and the limits on their agency imposed by other actors at other scales (Gunderson and Holling 2002).

Christensen and Krogman (2012:5) introduce the concept of social thresholds within social-ecological management practices as "collectively recognized points that signify new experiences," which in their case study included having power in decisionmaking processes. From a social-ecological viewpoint, Kirmayer et al. (2011) found that sources of resilience in an indigenous case study included the role of collective history in identity, and the existence of individual and collective agency. In some situations, actors have sufficient governance authority to shape adaptation or even transformation of an ecological system (Folke et al. 2005) but in the case of indigenous societies faced by overwhelming external forces, the ability to take action is likely to be constrained by more powerful interests, and cultural resilience may suffer (Turner et al. 2013).

Cultural resilience is still a nascent concept in the social-ecological resilience literature, and a number of authors have called for more theoretical development in the application of resilience concepts to community and culture (Buikstra et al. 2010, Ross et al. 2010), and in particular how societies are impacted by and endure crisis (Adger 2000, Davidson 2010). The term "cultural resilience" derives from two different strands of literature. One strand, originating in social psychology generally uses resilience to refer to the ability of individuals, and to a lesser extent communities, to positively adapt despite adversity (Elsass 1992, Luthar 2006). In a review article, Fleming and Ledogar (2008:3) define cultural resilience as "the capacity of a distinct community or cultural system to absorb disturbance and reorganize while undergoing change so as to retain key elements of structure and identity that preserve its distinctness." The other strand of literature derives from social-ecological resilience thinking. It only recently appeared as a concept distinct from social resilience, and uses the term to describe the qualities of interactions between cultural groups and their environments. In this tradition, Crane (2010:2) defines cultural resilience as "the ability to maintain livelihoods that satisfy both material and moral (normative) needs in the face of major stresses and shocks; environmental, political, economic or otherwise." For the purposes of this paper, both definitions are useful: our interest is in the response of a Māori collective to external changes and shocks, and in particular what aspects of their deriving social-ecological context has been retained or preserved by these communities to retain both identity and material and moral needs.

Inherent in both the social-ecological and cultural resilience literature is a fundamental contradiction in the play-off between stability and change. If resilience is "the capacity of a system to undergo change while still maintaining the same structure, functions and feedbacks, therefore identity" as suggested by Walker et al. (2010:2; emphasis added), but changes in structure, functions, and feedbacks are required to maintain a resilient system (Berkes and Turner 2006), then by the Walker et al. definition, the system will no longer be resilient. As Folke et al. (2005) explain, new organizational structures, roles, and knowledge flows may be necessary to respond to threats to the integrity of a set of social-ecological relationships. This suggests that resilience is compatible with, and at times dependent upon, changed structures, functions, and feedbacks.

What, then, is the unique characteristic of a resilient system? Is it the ability to change (the first part of Walker et al.'s 2010 definition) or the ability to maintain stability (the second part)? If it is both, and this is the implication of the definition, yet involves changes in Walker et al.'s defining "structure, functions and feedbacks," then what precisely is the hallmark of stability? Is it possibly to do with the final term "identity"? The research reported in this paper, initially intended as an intrinsic case study, unintentionally came up against this fundamental conundrum. In considering the relationships between cultural resilience and the social-ecological system within which the culture is embedded, it became evident that the retention of a cultural identity was not 
necessarily incompatible with social-ecological transformation, despite significant changes in "structures, functions and feedbacks". The question that the research ultimately sought to address was whether resilience heuristics adequately explained what is maintained to support the identity of a resilient system, as opposed to what is adapted or transformed.

\section{METHODOLOGY}

Resilience is fundamentally a temporal concept, involving observations of how a system responds to changing circumstances over time. The transformation of the ecological system of the LTFT lands in the mid-20th century had been preceded by over a century of radical change in economic, political, and social factors since colonization. A case study approach, involving both a historical review and a study of present-day perspectives, was determined to be an appropriate way of drawing together the threads to understand the processes of change and response.

The research design was guided from the start by the need to develop strong relationships with the tribal group and to ensure that it accurately reflected their experiences (Smith 1999). The history of change was in part developed from a desktop historical review, and in part from being permitted access to tribal records. The material was analyzed in a way analogous to an institutional history (Shambu Prasad et al. 2006), to reveal historical turningpoints in the tribe's relationship to their social and physical environment (Christensen and Krogman 2012). For the presentday perspectives, semistructured interviews were undertaken using a constructivist approach (Jones et al. 2006) and shaped by phenomenology (Merleau-Ponty 1962) because of the strong importance of understanding experiences through the eyes of the tribal members. The case study involved a large group of Māori families who are all part-owners of the LTFT lands, affiliate with the Ngāti Tūwharetoa tribe, and who formed the Lake Taupō Forest Trust (LTFT) as their representative entity in 1968.

Prior to the research commencing, a Memorandum of Understanding was developed with the LTFT leaders. This required that key informants were defined by the leaders; that the transcribed interviews were returned for checking to the interviewees; that the researcher was accountable to the tribe through giving a series of written reports and verbal presentations, and that the research as a whole was reviewed by delegated members of the Trust prior to publication. The researcher (coauthor) spent considerable time living in the community during the period of the research, establishing relationships and gaining a first-hand understanding of the context of the case study.

The data gathering first involved interviews with four key informants to draw from their rich understanding of tribal history and affairs. Family members living within the tribal region were then selected for semistructured interviews. All were either landowners or descendants of landowners yet to formally inherit their shareholdings (for the sake of simplicity, all are called landowners). Interviews were conducted mainly in English, and although Māori phrases were frequently used, the interviewer (coauthor) was competent in the Māori language. A total of 36 participants were interviewed, ranging in length from 30 minutes to 4 hours. Following their reviews of the transcripts, 31 participants consented to their interviews being included in the analysis.
The aim of these interviews was to elicit the participants' perspectives of their relationships with the land and forests. Questions covered three broad areas: first- and secondhand, i.e., being told by elders, participants' knowledge of hopes and concerns at the time when the afforestation lease was being considered (sometimes this knowledge was secondhand, having been told by elders), participants' values in relation to the land and forests, and their hopes and concerns for the future. The transcripts were then analyzed inductively, allowing themes to emerge from the data (Boyatzis 1998) using the software package NVivo $9^{\mathrm{TM}}$.

The researcher was also given access to a great deal of historical tribal documentation relating to past negotiations over land and forestry. These archive documents were previously unpublished and included meeting minutes, internal correspondence, court proceedings, and historical interviews. The institutional history was developed from both published sources and these historical documents. The account was then checked by the key informants who were closely involved with the LTFT.

Both the interview analysis and institutional history were then reviewed through the lens of resilience heuristics. The account below is a brief overview of findings from the interviews and history, followed by a fuller discussion of the interplay between resilience, adaptation, and transformation in the social-ecological and cultural dynamics. The wider findings of the study are more fully reported in Rotarangi (2011) and Rotarangi (2012).

\section{FINDINGS}

\section{Māori cultural concepts}

Māori describe themselves as tangata whenua or people of the land, and are New Zealand's indigenous people. Tangata means people, and whenua translates to both land and placenta (Ryan 2005), the combined term thus capturing the inseparable relationship between people and place in Māori culture. Articulating a cultural worldview in summary is difficult, but a brief introduction of key cultural concepts is necessary to provide context for our later discussion in which we describe how the people, their cultural values, and land affiliations have been affected by large-scale commercial forestry.

In Māori custom, every aspect of creation including heaven, earth, spirits, animals, plants, and humans, is genealogically connected. This worldview creates the obligation for Māori to maintain the well-being of not only their human kin but also of their natural resources as if they were family members (Awatere 2003, Reid 2005). This guardianship role is not solely as environmental protectors, but includes the active use of the environment for the social well-being of the people.

Māori describe land as a source of identity, and its retention as being vital to their well-being, and are particularly empowered by and connected to land that their ancestors have also occupied and used. As with land, Māori maintain a close mythological, genealogical, and practical relationship with forests for their sustenance, social and spiritual well-being.

Another aspect of Māori worldview that stems from these genealogical connections is their preference for collectivism. The Māori language is unequivocally framed in the collective, and individual terms are uncommon. This extends to economic 
activities, whereby the Māori economic ideal is for co-operative enterprise for the well-being of the community (NZIER 2003).

\section{Ngāti Tūwharetoa history}

Prior to the 1840 proclamation of British sovereignty, the entitlement of Māori to govern themselves and their lands was unquestioned. In the case of Ngāti Tūwharetoa, this authority related to approximately 1.2 million hectares centered around Lake Taupō. The period from 1840 to 1863 was a time of constitutional flux as New Zealand attempted to establish a jurisdiction that simultaneously recognized the Crown's authority and Māori autonomy. In 1863, tensions over the colonial desire for more land, and Māori resistance, culminated in the Crown declaring war on Waikato tribes adjacent to Tūwharetoa. For the next decade civil war engulfed the central North Island including Tüwharetoa. In the wake of military conquest and subsequent growth of the settler population, the balance of power in the region changed significantly.

Tūwharetoa were confronted by the full significance of the imposition of a European system of land ownership, and subjected to numerous fast-paced shocks and pressures, in particular in relationship to land autonomy and resource governance. During the latter part of the 19th century, significant amounts of land were lost to the tribe, and they entered into a long period of poverty and struggle to retain their remaining lands.

In response to these pressures, the tribe undertook a number of actions and complex negotiations that ultimately led to radical transformations of the environment, as well as governance and economic arrangements. It is clear that these decisions were strongly shaped by the changing political, economic, and legal context that constrained the tribe's sovereignty and limited their ability to continue traditional life ways. However, the tribe itself also had some degree of agency, and collectively made some decisions that in some respects seem counterintuitive if cultural resilience is assumed to be dependent on the stability of a socialecological system.

An early governance innovation occurred in 1887 when tribal chief Horonuku Te Heuheu Tūkino IV gifted the tribe's ancestral mountains to the Crown. In this process he relinquished the tribe's sole autonomy over the sacred area but he effectively ensured the land was never lost to private ownership. These mountains formed the nucleus of New Zealand's first national park, now a World Heritage area.

In 1906 his son, the chief Tureiti Te Heuheu Tūkino, entered into a commercial agreement to harvest much of the indigenous forest on what later became the LFTF lands. Tureiti was attempting to progress tribal economic development while ensuring the land would remain in tribal ownership for at least the duration of the agreement. Although leases involving royalties had been used previously in New Zealand, this agreement was unique owing to the scope of the proposed infrastructure and the equal benefit arrangement for the 800 Māori landowners. Perhaps because of the distinctive arrangement, the agreement stagnated for the next 35 years and further disadvantaged the landowners by effectively locking up the land from any other use. The indigenous forest produced no income, no infrastructure was built, and the royalties paid did not cover the cost of rates and taxes that accumulated during this time (Walzl 2004).

Having suffered a further generation of poverty and with the indigenous forest still largely standing, the owners were then faced with a prohibition order by the government to prevent commercial timber harvest while the Crown itself attempted to purchase the land. Despite their deprivation, the tribe's leaders and people stood united and refused the Crown's offers. In 1943 the government released its prohibition order and Ngāti Tūwharetoa owners finally regained independence over their land and its resources.

In 1950 the New Zealand Government passed the Māori Purposes Act, under which Māori would lose control and/or ownership of their land if it was not used productively. Faced with land loss, the tribe acted quickly and communally, starting to harvest native forest to create collective tribal revenue and converting some of the land into pasture for small farms.

A further shock to the tribe was the recognition in the 1960s of the harmful environmental effects of the runoff entering Lake Taupō from the farms that by then surrounded much the lake. An Officials Committee Study Group recommended that afforestation by planted forests was a key solution to reducing the nutrient flow into the lake, particularly for the eastern shores of the lake where the LTFT lands are located. The landowners acted collectively to seek a solution. They considered the option of undertaking afforestation themselves, however, they were not prepared to risk losing the land because it would be required as security for capital. They therefore formed the LTFT to collectively represent 58 subtribes, and negotiated an afforestation lease with the Crown.

This led to the creation of a 32,771-hectare planted forest, the largest ever of the government's Māori lease forests. The 1968 forest lease led to a further transformation in ecology and land use, from indigenous forest and marginal pasture, to a vast singlespecies planted forest. Furthermore the land management and governance structures were transformed from family-based decision making to a multifaceted partnership between the forest manager, collective family land holdings, tribal management committees, and forest regulators.

In this process, the tribe introduced two important innovations for the time. First, they negotiated the terms of the afforestation lease to reflect their own priorities, so that the first three management objectives for the planted forest were to prevent erosion reaching waterways and the lake, to protect wildlife including fish, and to protect sacred sites. The fourth objective, a profitable forest, was subservient in the lease agreement to the first three. This was highly innovative for the late 1960s, an era in which environmental concerns were given low priority. Second, the landowners made a collective commitment, involving the 58 subtribes, each relating to each land title, agreeing to manage their combined lands as a single asset, and to share in the risks of the forestry lease. For some landowners this meant converting their working family farms into planted forest, for others this meant allowing the cutting down of their native forest to allow for afforestation. Table 1 summarizes the key actions undertaken by the LTFT owners that involved significant adaptations or 
Table 1. Key adaptations and transformations of the social-ecological system.

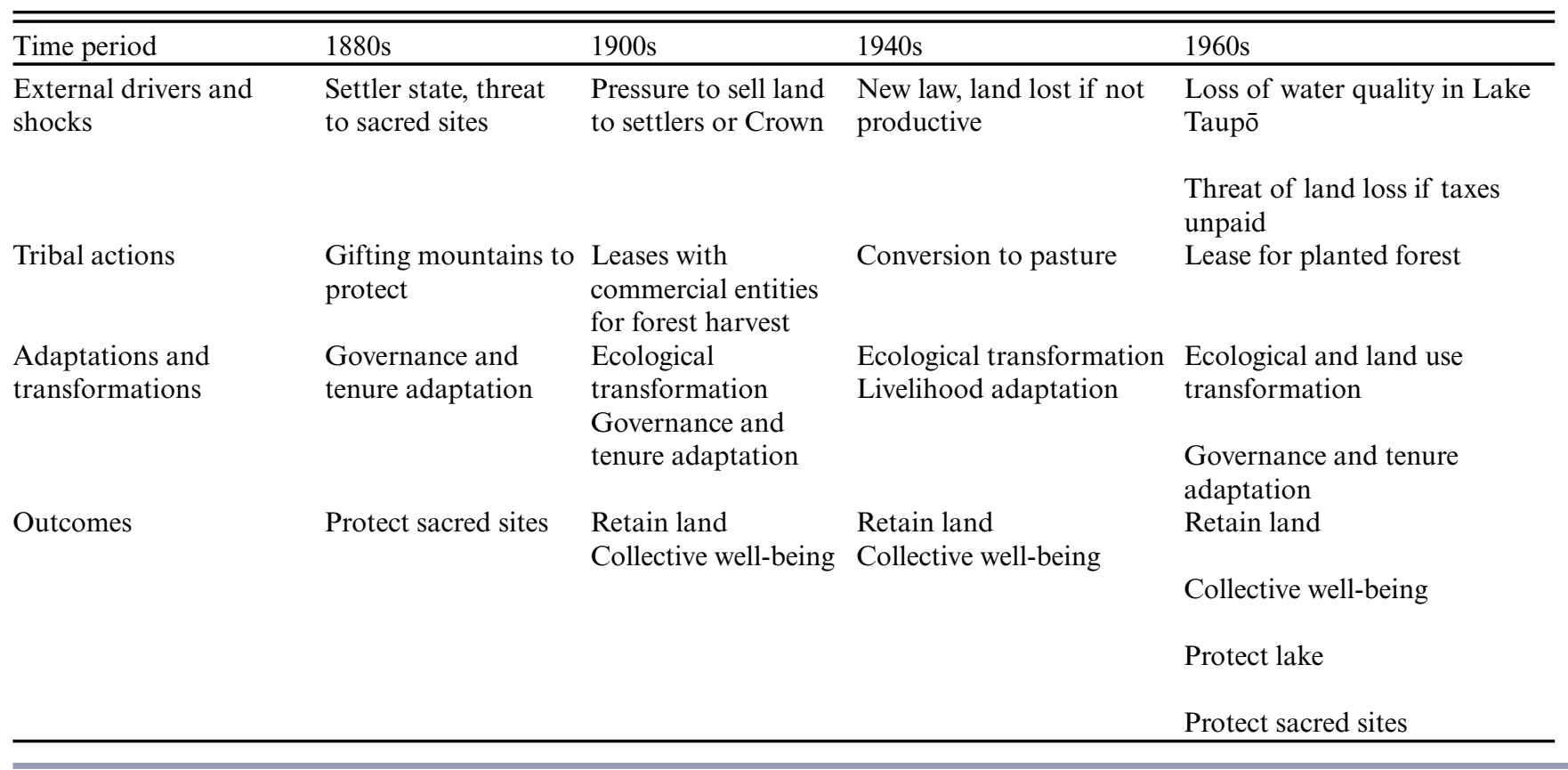

transformations in ecological and social aspects of the system but protected culturally crucial elements.

\section{Present-day perspectives}

The resilience story of the LTFT can only be partly told through historical documents. To introduce the living voice, discover present-day perspectives, and look for continuities between past and present, we turn to the voices of the landowners.

When asked for their recollections, or what they had been told by elders, as to the hopes and concerns of the collective when the afforestation lease was being considered over 40 years previously, it was evident that there was considerable concern at the time over the potential for loss of authority over their lands:

One of the main concerns that I can recall coming out
of the meeting was retaining the control of the land and
they were adamant they did not want to lose control of
the land ... they would be thinking of their children and
grandchildren. (LTFT3)

The overriding wish was that the planted forest would benefit the future generations by providing future income and employment:

We don't own land, the land owns us, and it comes back to that kaitiakitanga [guardianship] principle of protection for the next generation. So I can very much see that foresight of those in the 1960s that made the decision to go into forestry, [they] were looking at their grandchildren and the benefits that they will get out of it. (LTFT18)

By establishing the forest, the collective would achieve the longterm retention of the land, albeit with diminished control, and would also be able to protect sacred sites and maintain at least some of their cultural practices (tikanga):
... [T The original signatories to the lease, they've always said that the tikanga had to be observed, the Tūwharetoa values had to be nurtured first of all, even before any consideration of the commercial values ... and they made sure that happened. (LTFT1)

When asked about their cultural values for their land today, the responses strongly reflected what was evident in the historical tribal documents. The most commonly reported value was the retention of the land: "What's really non-negotiable? In terms of the land ... that we don't lose it, we don't endanger it in any way, shape or form" (LTFT30). A further cultural value that drove the decision making was that of acting for collective social well-being:

Those groups of people from the mountainside, below the mountain and beside the lake, those groups of people came together with the understanding that they need to plant these trees for the rest of the family... so that thought keeps coming true, all the time, right until today and it should stay the same. (LTFT14)

Participants also identified the protection of sacred sites, and the ability to continue cultural practices, as further fundamental cultural values. Their ongoing responsibilities of guardianship meant that the health of the adjacent Lake Taupō was also crucially important:

The Lake is our source of life, we describe that as the ahuru mowai, in English it is like the womb, the sustenance of the tribe... the Lake has such an important cultural part that arguably you won't find any words that define it that way, but it was inherent in our thinking. Yes we are prepared to protect that Lake because it has significance to us beyond any dollar value. (LTFT17) 
Although financial dividends from the forest were important, these were commonly described by interviewees as being of less concern than environmental and social outcomes. Finally, although most interviewees expressed a desire for more diversification within the forestry operation to allow for more landowner participation in land management and greater collective benefit, none indicated a desire to change the land use, and many were overtly proud of the forest: "When people talk about Tūwharetoa, they talk about the mountains, the Lake and the [planted] forest" (LTFT27); "Certainly, the forest is awesome, you know we're proud of that." (LTFT18)

It was clear that the forest was seen as making a positive contribution to the tribe in many tangible ways, and importantly had become an element of the self-identity of the tribe.

\section{Reflecting on resilience}

As shown in Table 1, the interconnected cultural and socialecological story of the LTFT was of a major adaptation and transformation over the past 150 years. Ecologically, the area was transformed from an indigenous forest, to farmlands and cutover forests, and then to a vast single-species planted exotic forest. External economic and political drivers led to a series of major adaptations of governance arrangements, changing from unfettered family authority, to a period of little control over their own lands and resources, to today a greater, but still shared, role in governance. Tribal livelihoods also went through many changes from traditional practices, through periods of poverty and subsistence living, through involvement in forest clearance and farming, a diaspora of significant numbers of tribal members to elsewhere in New Zealand, to today some employment within the forest operations and at a management level.

From a resilience perspective, the social-ecological system that was in place 170 years ago has been largely transformed to a new state: from an indigenous forest and adjacent lake from which the owners gained sustenance using traditional practices, to an exotic planted forest generating logs for timber and export, managed using modern forest techniques, and providing some local employment, albeit not as much as anticipated. However, something has persisted, and that is the Ngāti Tūwharetoa culture, a distinctive collation of worldview, values, practices, and interrelationship between people and place. Despite the many changes and shocks of the past, the owners today still retain strong affiliations with their land and strongly identify as Māori, and in particular as members of Ngāti Tūwharetoa. The transformations have not been at the expense of their cultural resilience.

The LTFT experience fits with Fleming and Ledogar's (2008:3) definition of cultural resilience, whereby the cultural system has absorbed disturbance and reorganized while undergoing change "so as to retain key elements of structure and identity that preserve its distinctness." Crane's (2010:2) definition of cultural resilience is perhaps less fitting to the circumstance because the resilience revealed in the narrative above is clearly not just the maintenance of "livelihoods that satisfy both material and moral needs," in which the forest plays but a minor role at present, but more to do with the maintenance of cultural identity, values, and practices.

The resilience of the culture can be partly ascribed to the tribe's ability to innovate and change aspects of their governance structures, economic activities and land uses. They responded to massive shocks and slower change cycles by both adapting and transforming aspects of the social-ecological system within which their culture is embedded. In resilience terms, although they were subject to forced transformation from colonization, political, legal, and economic drivers, they were at the same time involved to some extent in active transformation of the system (Folke et al 2010). It was the tribe's agency, albeit limited, that enabled them to insist upon clauses in the lease agreement to protect the water quality and sacred places, and to put in place collective management of the land despite the individualization of ownership that had been forced by colonial laws. From a socialecological systems perspective, our case study had all the hallmarks of a transformational change (Walker et al. 2004): on the societal side, changed organizational and institutional arrangements, and changing power relationships; and on the ecological side, changed defining state variables. However, being able to identify adaptation and transformation did not tell the whole resilience story. From a cultural perspective, the system was resilient in that the culture, including its defining relationship with the environment, was able to "absorb disturbance and reorganise while undergoing change" while still retaining "identity" (Walker et al 2010:2), even though changes were evident in structures, functioning, and feedbacks. In other words, we identified (a) cultural resilience in the face of adaptations and transformations in the social-ecological system, and (b) the retention of identity despite changes in some of the apparent underpinnings of identity. Both discoveries generated further questions. In relation to the first, the resilience concepts of adaptability and transformability were helpful in theorizing the change processes, but did not reflect the elements of stability that were core to the LTFT story. The intriguing question was not about the existence and process of change, but the retention of cultural resilience in the face of change. In relation to the second, if the defining feature of resilience is the retention of identity (Walker et al. 2010), and yet we were observing change in structure, functioning, and feedbacks, what was it that was retained that allowed the continuation of cultural identity, and how could this be theorized?

\section{RESILIENCE PIVOTS}

Resilience thinking has developed effective heuristics concerning change, i.e., adaptation, transformation, panarchy, but less focus has been given to the notion of stability, or theorizing the stable characteristics of a resilient system. When the history of LTFT and the present-day perspectives were considered together, it was evident that the tribe's adaptive or transformative actions were in response to challenges to certain core elements of cultural wellbeing. One of these was the retention of the land. Relationships to land are fundamental to tribal identity, and the LTFT owners were willing to accept tenure and governance arrangements that removed their control of the land to retain ownership. The transformation of their natural environment was also largely to protect themselves against threats to land loss, and in part to generate a livelihood. These changes, dramatic though they were, could be interpreted as Christensen and Krogman's (2012) "social thresholds" in that they were collectively agreed points of change. The tribe's responses enabled the people to retain their attachments to place and thus maintain resilience in a cultural sense.

The collective decision to forgo further farm development and to enter into an afforestation lease was also culturally driven, 
motivated by a desire to improve the water quality of Lake Taupō that reflected the extreme reverence and responsibility that the tribe holds toward the lake. Another key theme was the desire of the landowners to pursue the collective well-being of both current and future generations, rather than individual interests. Their trust in leadership and desire to act for the communal benefit appears throughout the historical and present-day narratives as an important cultural trait. This communalism, both for present and future generations, enabled a capacity to quickly respond to challenges and crises, often resulting in unique arrangements negotiated at a time of crisis. The innovative structuring of the Trust to maintain individual family blocks but manage the forest as a whole is another example whereby a unified approach both emerged from and contributed to cultural resilience.

Although there were undoubtedly other cultural elements that shaped the LTFT story, there were four, i.e., the retention of land, the protection of the lake, the protection of sacred sites, and the well-being of the collective, that stood out as being pivotal in the sense that the owners were willing to change or sacrifice many other components of the social-ecological system that were within their power to influence, in order that these might endure. Figure 2 indicates this diagrammatically, showing these as "pivots": core cultural-social-environmental relationships, central to cultural resilience, which endured despite ecological transformation, and despite, or because of, adaptations in tenure, livelihoods, and governance.

Fig. 2. Resilience pivots as the stable core of a system. The cultural resilience of the Lake Taupō Forest Trust owners was supported by the core resilience pivots of (a) the retention of their land, (b) active protection of the health of Lake Taupō, (c) active protection of their sacred sites, and (d) new structures that maintained collective decision making processes. Adaptations within the social system included tenure, livelihoods, and governance, while transformations occurred in the ecology and land use.

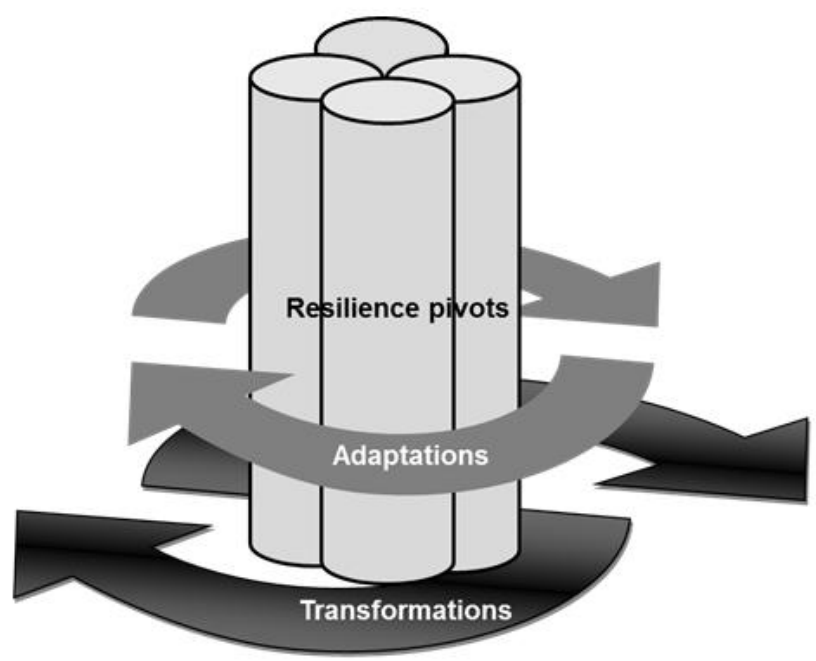

A pivot is defined as "a person, thing, or factor having a major or central role, function, or effect" (http://www.merriam-webster. com/dictionary/pivot). We adopted the term to describe the elements that emerged as the stable core of cultural resilience in this case study. The term "pivot" refers both to the fact that these elements were pivotal to the integrity of the cultural system within the wider social-ecological setting, and also that they were points of definable stability in a complex landscape of adaptation and transformation of other parts of the social-ecological system. Figure 2 shows the pivots as core stable elements of cultural resilience, surrounded by trajectories of change: the adaptations and transformations to the social-ecological system.

The resilience pivots identified in the LTFT case study were clearly evident in both the historical review and in the current-day perspectives of interviewees. The pivots are all strongly reflective of Māori cultural perspectives: the importance of tūrangawaewae,

a place to stand; of whakapapa, and whanaungatanga, relationships and acting for the good of all; and of kaitiakitanga, the responsibility for environmental and social guardianship. For Ngāti Tūwharetoa, these can be seen as shared values of such high importance that they fought to ensure that they endured in the face of numerous shocks and changes to the social and ecological systems, which consequentially altered other elements of culture, such as those dependent on traditional livelihoods and tribal authority. By their agency in adapting and transforming to protect the resilience pivots, the tribe managed to retain key elements of their cultural identity, and to weld on to this a compatible identity as forest owners. Without the retention of these hard-fought pivots, we suggest that cultural resilience would have been far weaker, and that the planted forest would have emerged as antagonistic to cultural values rather than complementary.

\section{DISCUSSION}

We had hypothesized that the owners would dislike the forest, given that it was a monoculture of a non-native tree species, that it had removed the ability for them to use their land in other ways, and that the governance of the land was largely removed from their control because of the long-term lease arrangement. However, almost all of the interviewees were accepting of the forest, despite it not producing the economic returns or employment that had been promised at the outset, with over half describing how the forest and related leadership enhanced their identity. The explanation for this somewhat counterintuitive outcome that emerged from the analysis was that the owners had entered into the arrangement as a collective decision, had ensured in doing so that certain fundamental values were maintained, and that the forest now supported their identity as Tüwharetoa. By acting on their limited degree of agency and influencing what to protect, and what to adapt and transform, the tribal collective both retained their cultural identity (Fleming and Ledogar 2008) and met their material and moral needs (Crane 2010).

Analysis of this case study through the resilience lens revealed an ongoing dynamic over time between cultural resilience and socialecological resilience. The boundaries between cultural, social, and ecological elements of any linked system are blurred, and this was certainly the case with the LTFT case study. The history reveals many linkages between cultural components, mainly values and 
practices, social components, i.e., governance and economics, and ecological components, forests, farms, lake, and although cultural resilience has been set off against social-cultural resilience throughout this paper, it has been done simply to retain some clarity of focus. From a more integrated perspective, it must be recognized that there are continual interactions and feedbacks between cultural, social, and ecological components of any system, and one of the strengths of the resilience concept is its applicability across all of these aspects.

It is questionable whether it could be claimed that the system has generalized resilience (Folke et al. 2010). A compartmentalized response might be to say that the system over time exhibited cultural resilience, but not social-ecological resilience. This perspective ignores the strength of linkages between culture and environment, and between cultural structures and social structures. Our interpretation is that over the period of the case study, the cultural-social-ecological system as a whole exhibited some elements of transformation, some elements of adaptation, and some elements of resilience. As indicated in Figure 2, the ecology and land use of the LTFT's extensive lands were transformed, while adaptations within their social system included tenure, livelihoods, and governance. Cultural resilience remained strong in the face of the transformations. This suggests that the "three possible responses to disturbance" of transformation, adaption, or resilience (Davidson 2010:1144-1145) can occur simultaneously in a social-ecological-cultural system, rather than being mutually exclusive.

Walker et al.'s (2004) definition of resilience suggests that resilience involves a system maintaining "essentially the same function, structure, identity, and feedbacks" while the Walker et al. (2010:187) definition refers to the system maintaining "the same structure, functions and feedbacks, therefore identity." The LTFT owners' maintenance of a strong cultural identity was achieved as a result of both initiating and enduring significant adaptations to governance structures, economics and tenure, and transformations in the native ecologies and land use. Hence the "structure, functions and feedbacks" across the social-ecologicalcultural system showed significant change over time, while Walker et al.'s (2010) overarching criteria of "identity," as in cultural identity in this case, was maintained through time. The retention of identity and the cultural resilience of the tribal group were clearly strongly linked, and if resilience can, in this case at least, be consistent with changes in structure, functions, and feedbacks in a system, then perhaps the slippery concept of "identity" is the core signifier of a resilient system. However, this observation does little to help conceptualize the nature of stable elements in a resilient system, and this point became of prime interest for this study.

The concepts of adaptation and transformation inform part of the LTFT story, but are less helpful in providing a framework to consider what did not change, or clarifying what it was about "identity" that was stable. Without grasping what was retained in the social-ecological-cultural system relationships to support the cultural system, it was not possible to understand why the collective chose to act the way they did, at times in ways that seemed quite at odds with cultural values, what it was that they fought so hard to retain, and what contribution this could make to the maintenance of a resilient culture in the face of massive social-ecological shifts. The resilience pivots concept offers a way past this impasse by turning the focus on to what is maintained in a resilient system, as opposed to what is changed. Pivots differ from social thresholds (Christensen and Krogman 2012) in that we sought to define the qualities of the stable core that supports resilience, rather than points of change. The concept of resilience pivots was developed to articulate the stable relationships that are at the heart of a resilient system.

Applied to cultural resilience, a resilience pivot is a matter of fundamental and enduring importance to a cultural group, central to cultural identity, which is tangibly supported by the wider social-ecological system. For cultural resilience to be maintained, changes in the associated social-ecological system must be compatible with these core qualities or values. For example the planted forest, although wholly foreign to traditional Māori culture, supported collectiveness, protected the lake and sacred sites, and enabled the land to be retained in tribal ownership and therefore was considered an appropriate land use, but only, we suggest, because the owners had asserted their limited agency to establish and retain the pivots.

At the beginning of this paper we referred to Cote and Nightingale's (2012) challenge that resilience thinking needs to grapple with the normative question of "resilience of what and for whom?" In other words, what system are we talking about, and whose resilience is being considered? For the purposes of this case study, the "what" was the cultural system and its interdependencies with the social-ecological system, and "for whom" was the tribal land owners. Although we identified certain resilience pivots as core elements of the cultural resilience of the landowners, other pivots would almost certainly emerge if other perspectives were taken of the system. For example, if "for whom" was a different cultural group, or the native ecology, a quite different set of pivots is likely to be core to their continued identity. The concept of resilience pivots may assist with differentiating between what different types of resilience exist within the same system, by asking what the core pivots are, and for whom they support a distinctive identity.

\section{CONCLUSION}

The research presented in this paper applied resilience thinking, and its heuristic tools, to a historical case study in which an indigenous group has displayed cultural resilience despite significant change in the ecological and social systems associated with their lands. Historical data and present-day narratives revealed that, despite difficulties and disappointments, the landowners were willing to negotiate and accept radically different land management regimes to protect core cultural elements. The key resilience concepts of adaptation and transformation were helpful in analyzing the trajectory of change, but fell short of representing the elements of stability that supported the cultural resilience of the landowners.

Our case study identified four repeatedly mentioned stable elements of the social-ecological-cultural system that had been maintained, in the face of major disruptions, through the agency of the landowners at key points of their collective history. These were the retention of their land, through entering into long-term leases with external parties for forest plantations, the adoption of new structures that maintained collective decision making, the protection of the health of the lake, and the protection of sacred 
sites. These actions ensured that core cultural values were maintained while other parts of the system underwent significant adaptations and transformations. These four elements were thus pivotal to maintaining cultural resilience.

In analyzing the case study through the resilience lens, we found that that it offered some challenges to resilience concepts. First, it was evident that, rather than being mutually exclusive, the three possible responses of transformation, adaption, and resilience can occur simultaneously in a social-ecological-cultural system. Second, we observed significant changes in systemic structure, functions and feedbacks alongside the retention of strong cultural identity. We suggest that this is evidence that Walker et al.'s (2010) overarching concept of "identity" may be the core signifier of a resilient system. If a resilient system is one that has a stable identity, then to characterize resilience it is necessary to identify those stable elements of the system that are core to identity. It is these elements, pivotal in this instance to cultural resilience, that we have identified in this study and called "resilience pivots." Applying the concept more generally, resilience pivots are those elements of a resilient system that remain stable despite adaptation or even transformation of other elements of that system, and in doing so support the maintenance of the system's distinctive identity.

The concept of resilience pivots is complementary to other resilience concepts, yet offers a distinctive focus on the fundamental elements that are core to the stability and integrity of a resilient system. For our purposes, the concept helps make sense of cultural resilience in relation to adaptation and transformation in the culture's associated social-ecological system. Further work is required to assess whether the concept may also offer insights into the stability of other cultural, ecological, social, or social-ecological systems.

${ }^{[1]}$ This is one of two New Zealand case studies that are reported more fully in Stephanie Rotarangi's 2011 PhD thesis Planted forests on ancestral land: the experience and resilience of Māori land owners. Both case studies contributed to the emergence of the "pivots" concept, but for the purposes of brevity and clarity we have reported only one of the case studies here.

Responses to this article can be read online at: http://www.ecologyandsociety.org/issues/responses. $\mathrm{php} / 6262$

\section{Acknowledgments:}

Funding for this project was provided by the Te Tipu Pūtaiao Doctoral Fellowship as administered through New Zealand's Ministry of Science and Innovation. Further funding was also provided by the New Zealand Institute of Forestry and Scion. The research was coordinated by the Centre for Sustainability: Agriculture, Food, Energy, Environment (CSAFE) at the University of Otago. Guidance and helpful suggestions were provided by Dr Hauiti Hakopa, Dr Parnell Trost, and Professor Hugh Campbell. The authors are very grateful to the families of Lake Taupō Forest Trust and Marearoa C Incorporation for their participation and significant logistical support.

\section{LITERATURE CITED}

Adger, W. N. 2000. Social and ecological resilience: are they related? Progress in Human Geography 24(3):347-364. http://dx. doi.org/10.1191/030913200701540465

Adger, N., K. Brown, and D. Conway. 2010. Editorial: Progress in global environmental change. Global Environmental Change 20:547-549. http://dx.doi.org/10.1016/j.gloenvcha.2010.07.007

Anderies, J. M., B. H. Walker, and A. P. Kinzig. 2006. Fifteen weddings and a funeral: case studies and resilience-based management. Ecology and Society 11(1): 21. [online] URL: http:// www.ecologyandsociety.org/vol11/iss1/art21/

Awatere, S. 2003. Tangata Whenua perspectives. Report for the New Zealand Land Treatment Collective. Landcare Research, Palmerston North, New Zealand.

Berkes, F., J. Colding, and C. Folke, editors. 2003. Navigating social-ecological systems: building resilience for complexity and change. Cambridge University Press, Cambridge, UK. http://dx. doi.org/10.1017/CBO9780511541957

Berkes, F., and N. J. Turner. 2006. Knowledge, learning and the evolution of conservation practice for social-ecological system resilience. Human Ecology 34(4):479-494. http://dx.doi. org/10.1007/s10745-006-9008-2

Boyatzis, R. E. 1998. Transforming qualitative information: thematic analysis and code development. Sage, Thousand Oaks, California, USA.

Buikstra, E., H. Ross, C. A. King, P. G. Baker, D. Hegney, K. McLachlan, and C. Rogers-Clark. 2010. The components of resilience: perceptions of an Australian rural community. Journal of Community Psychology 38(8):975-991. http://dx.doi. org/10.1002/jcop.20409

Carpenter, S., B. Walker, J. M. Anderies, and N. Abel 2001. From metaphor to measurement: resilience of what to what? Ecosystems 4(8):765-781 http://dx.doi.org/10.1007/s10021-001-0045-9

Christensen, L., and N. Krogman. 2012. Social thresholds and their translation into social-ecological management practices. Ecology and Society 17(1): 5. http://dx.doi.org/10.5751/ ES-04499-170105

Cote, M. and A. J. Nightingale. 2012. Resilience thinking meets social theory: situating social change in socio-ecological systems (SES) research. Progress in Human Geography 36(4):475-489. http://dx.doi.org/10.1177/0309132511425708

Crane, T. A. 2010. Of models and meanings: cultural resilience in social-ecological systems. Ecology and Society 15(4): 19. [online] URL: http://www.ecologyandsociety.org/vol15/iss4/ $\underline{\operatorname{art19l}}$

Davidson, D. J. 2010. The applicability of the concept of resilience to social systems: some sources of optimism and nagging doubts. Society and Natural Resources 23(12):1135-1149. http://dx.doi. org/10.1080/08941921003652940

Elsass, P. 1992. Strategies for survival: the psychology of cultural resilience in ethnic minorities. New York University Press, New York, New York, USA. 
Fleming, J., and R. J. Ledogar. 2008. Resilience, an evolving concept: a review of literature relevant to Aboriginal research. Journal of Aboriginal and Indigenous Community Health 6 (2):7-23.

Folke, C. 2006. Resilience: the emergence of a perspective for social-ecological systems analyses. Global Environmental Change 16:253-267. http://dx.doi.org/10.1016/j.gloenvcha.2006.04.002

Folke, C., S. R. Carpenter, B. Walker, M. Scheffer, T. Chapin, and J. Rockström. 2010. Resilience thinking: integrating resilience, adaptability and transformability. Ecology and Society 15(4): 20. [online] URL: http://www.ecologyandsociety.org/vol15/iss4/ $\underline{\operatorname{art} 20 /}$

Folke, C., T. Hahn, P. Olsson, and J. Norberg. 2005. Adaptive governance of social-ecological systems. Annual Review of Environment and Resources 30:441-473. http://dx.doi.org/10.1146/ annurev.energy.30.050504.144511

Gunderson, L., and C. S. Holling, editors. 2002. Panarchy: understanding transformations in human and natural systems. Island, Washington, D.C., USA.

Jones, S., V. Torres, and A. L. Arminio. 2006. Negotiating the complexities of qualitative research in higher education: fundamental elements and issues. Routledge, New York, New York, USA.

Kirmayer, L. J., S. Dandeneau, E. Marshall, M. K. Phillips, and K. J. Williamson. 2011. Rethinking resilience from indigenous perspectives. Canadian Journal of Psychiatry. Revue Canadienne de Psychiatrie 56(2):84-91.

Luthar, S. S. 2006. Resilience in development: a synthesis of research across five decades. Pages 739-795 in D. Cicchetti and D. J. Cohen, editors. Developmental psychopathology: risk, disorder, and adaptation. Second edition. John Wiley and Sons, Hoboken, New Jersey, USA.

Merleau-Ponty, M. 1962. Phenomenology of perception. Routledge and Kegan Paul, London, UK.

New Zealand Institute of Economic Research Incorporated (NZIER). 2003. Māori economic development - te ohanga whanaketanga Māori. NZIER, Wellington, New Zealand.

Community and Regional Resilience Institute (CARRI). 2009. Definitions of community resilience: an analysis. CARRI, Oak Ridge, Tennessee, USA. [online] URL: http://www.resilientus. org/wp-content/uploads/2013/08/definitions-of-community-resilience. pdf

Reid, J. 2005. He whenua whakatipu: a draft sustainable development framework for Ngāi Tahu landholders. Working Paper No. 4. Agriculture Research Group on Sustainability, Christchurch, New Zealand. [online] URL: https://researcharchive. lincoln.ac.nz/handle/10182/5628

Ross, H., M. Cuthill, K. Maclean, D. Jansen, and B. Witt. 2010. Understanding, enhancing and managing for social resilience at the regional scale: opportunities in North Queensland. Report to the Marine and Tropical Sciences Research Facility. Reef and Rainforest Research Centre Limited, Cairns, Australia.
Rotarangi, S. 2011. Planted forests on ancestral land: the experience and resilience of Māori land owners. Dissertation, University of Otago, Dunedin, New Zealand.

Rotarangi, S. 2012. Plantation forest leases: experiences of New Zealand Māori. Canadian Journal of Forest Research 42 (9):1678-1686. http://dx.doi.org/10.1139/x2012-113

Ryan, P. M. 2005. The Reed dictionary of modern Māori. Reed Books, Auckland, New Zealand.

Shambu Prasad, C., A. Hall, and L. Thummuru. 2006. Engaging scientists through institutional histories. ILAC Brief No. 14. Consultative Group on International Agricultural Research (CGIAR). Institutional Learning and Change (ILAC) Initiative, Rome, Italy.

Smith, L. T. 1999. Decolonising methodologies: research and indigenous peoples. University of Otago Press, Dunedin, New Zealand.

Turner, N. J., F. Berkes, J. Stephenson, and J. Dick. 2013. Blundering intruders: extraneous impacts on two indigenous food systems. Human Ecology 41:563-574. http://dx.doi.org/10.1007/ s10745-013-9591-y

Walker, B., C. S. Holling, S. R. Carpenter, and A. Kinzig. 2004. Resilience, adaptability and transformability in social-ecological Systems. Ecology and Society 9(2): 5. [online] URL: http://www. ecologyandsociety.org/vol9/iss2/art5/

Walker, B., L. Pearson, M. Harris, K. G. Maler, C. Z. Li, R. Biggs, and T. Baynes. 2010. Incorporating resilience in the assessment of inclusive wealth: an example from South East Australia. Environmental and Resource Economics 45(2):183-202. http://dx. doi.org/10.1007/s10640-009-9311-7

Walzl, T. 2004. The Central North Island Inquiry: Māori and Forestry. Crown Forest Research Trust, Wellington, New Zealand. 